\title{
Internal stresses in Metal Matrix Composites in relation with matrix phase transformations
}

\author{
VAUTROT Lilian ${ }^{1,2, a}$, GEANDIER Guillaume ${ }^{1,2, b}$, MOUROT Mickaël ${ }^{1}$, \\ DEHMAS Moukrane ${ }^{1,2, \mathrm{c}}$, AEBY-GAUTIER Elisabeth ${ }^{1,2, \mathrm{~d}}$, DENAND Benoît ${ }^{1,2, \mathrm{e}}$ \\ and DENIS Sabine ${ }^{1,2, \mathrm{f}}$
}

${ }^{1}$ Institut Jean Lamour - UMR 7198 CNRS - Université de Lorraine - Parc de Saurupt - CS 50840 54011 Nancy Cedex France

\author{
${ }^{2}$ LabEx DAMAS - Université de Lorraine, Nancy, France \\ alilian.vautrot@univ-lorraine.fr, ${ }^{b}$ guillaume.geandier@univ-lorraine.fr, \\ cmoukrane.dehmas@univ-lorraine.fr, ${ }^{\mathrm{d}}$ elisabeth.gautier@univ-lorraine.fr, \\ ebenoit.denand@univ-lorraine.fr, fsabine.denis@univ-lorraine.fr
}

Keywords: metal matrix composite, X-ray diffraction, stresses, phase transformation, microstructure.

\begin{abstract}
For metal matrix composites, internal stresses are a key factor for understanding the interactions between matrix and reinforcements and the mechanical properties of the composite. From in situ high energy X-ray diffraction on a steel matrix composite reinforced with $\mathrm{TiC}$, the evolutions of the phase fractions and mean cell parameters of each phase during thermal treatment have been determined. In addition, a methodology is developed in order to get more information on the stress state evolutions in each phase during the treatment.
\end{abstract}

\section{Introduction}

Mass reduction (for example in transportation applications where reduction of fuel consumption and pollution are aimed) can be obtained, by using new lighter materials with at least the same mechanical properties as the former ones. Metal matrix composites (MMC) reinforced by ceramic particles allow to reach this goal. In our study, steel matrix composite reinforced by $\mathrm{TiC}$ particles obtained by powder metallurgy (mixture of $75 \%$ steel powder and $25 \%$ TiC powder) allow to reduce the density $\left(7 \mathrm{~g} / \mathrm{cm}^{3}\right.$ for this composite instead of $7.8 \mathrm{~g} / \mathrm{cm}^{3}$ for steel alone i.e. a decrease of $11.4 \%$ in mass). Final properties of MMC depend on the chemical composition, on the nature of the interfaces, on the microstructure of the matrix and on the stresses in the reinforcements and in the matrix. These stresses are generated during the heat treatment and result from the differences in the coefficient of thermal expansion between matrix and reinforcements $[1,2,3]$ and also from the phase transformations of the matrix that occurs during cooling and induce volume changes. The residual stress levels and distributions are a key factor for the final properties of the MMC [4, 5]. In a previous study [6], the evolution of the matrix and the reinforcements were analysed during the heat treatment using in-situ high energy $\mathrm{X}$ ray diffraction focusing on the structural aspects. In this paper, we focus on the internal stress analysis.

\section{Experimental setup}

Sample. A metal matrix composite has been elaborated using powder metallurgy by Mecachrome. $75 \%$ (vol.) steel powder and $25 \%$ TiC powder were milled and consolidated by hot isostatic pressing (HIP). The chemical composition of the steel is given in [5]. After hot isostatic pressing, the microstructure of the steel matrix composite (fig. 1) is non-homogeneous and presents two different areas : a steel area (pearlitic) without TiC particles called unreinforced area (lighter area) and a darker area being a mixture of $\mathrm{TiC}$ particles and steel. 


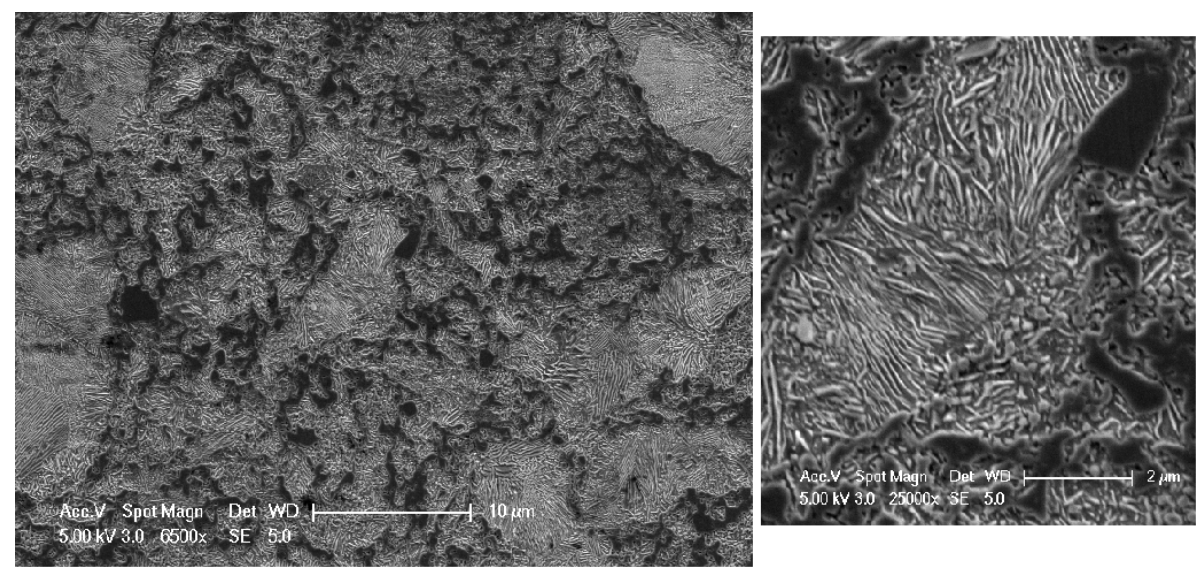

Fig. 1: Microstructure of steel matrix composite reinforced by $\mathrm{TiC}$ particles

High-energy X-ray diffraction. The X-ray diffraction (XRD) experiments were performed at the European Synchrotron Radiation Facility (ESRF, Grenoble, France) on the ID15B beam line. The in situ measurements were conducted using high enenergy X-ray synchrotron diffraction with a monochromatic beam of $87 \mathrm{keV}$. The high energy beam allowed to analyze a large volume of the sample (due to the low absorption of the sample) thus being representative of the bulk and lessen the surface effect. The transmitted signal is collected by a large area 2D detector that allowed to record the whole Debye-Scherrer rings. The important flux gives a high quality diffraction signal quickly, thus XRD frames can be recorded in a few second. By this method, we can follow Debye-Scherrer rings evolution during a thermal treatment.

For our experiments, the sample had a thickness of $6 \mathrm{~mm}$ in the beam direction and the beam size was fixed to $0.4 \times 0.4 \mathrm{~mm}$. About $1 \mathrm{~mm}^{3}$ of the sample is analyzed. The sample was heated to $1000^{\circ} \mathrm{C}$ thanks to a radiation furnace. This temperature was held during 30 minutes. Then, the sample was air cooled (at about $5^{\circ} \mathrm{C} / \mathrm{s}$ ). XRD frames were recorded every $3.5 \mathrm{~s}$ during this thermal treatment. These data are used to follow phase fractions and mean cell parameters evolutions and stress evolutions in each phase.

\section{Data analysis}

Global analysis by Rietveld method. In order to extract phase fractions and mean cell parameters from the XRD frames showing Debye-Scherrer rings, Rietveld method was applied [7, 8]. Data have been corrected and reduced (2 $\theta$, intensity) patterns using fit $2 \mathrm{~d}$ software [9] (fig. 2). (An integration of the intensities was performed all around the rings).

Stresses analysis. From the same corrected frames used for Rietveld analysis, a stress analysis has been performed applying the $\sin ^{2} \Psi$ method. Contrary to Rietveld analysis, an integration is performed only for a sector of $1^{\circ}$ of the ring using fit $2 \mathrm{~d}$ software and this operation is repetead all around the ring. Thus, we obtain 360 diffractograms ( $2 \theta$, intensity) for the 360 azimuths $(\delta)$ that constitute the ring. In order to extract stresses in each phase from these data, we have to determine the $2 \theta$ position of one peak in each phase. We have selected $\alpha(200), \gamma(200)$ and $\operatorname{TiC}(220)$, as they do not overlap with other peaks (fig. 2). Diffraction peaks are approximated by a Pearson VII function, that allows to reproduce the shape of our peak and to obtain their $2 \theta$ position. This operation is repetead for the three phases for the 360 azimuths and this, for all diffractograms collected during the thermal treatment. To avoid uncertainties in $2 \theta$ position due to the variation of the beam position in time, the average in $2 \theta$ position for the opposite azimuths $\left(\delta\right.$ and $\left.\delta+180^{\circ}\right)$ is calculated [10]. This step allows us to free ourselves of the exact knowledge of the position of the center of the ring. In order to apply the " $\sin ^{2} \psi^{\prime \prime}$ method, we have to convert our configuration to classical $(\Phi, \Psi)$ configuration (fig. 3). Indeed, each azimuth 

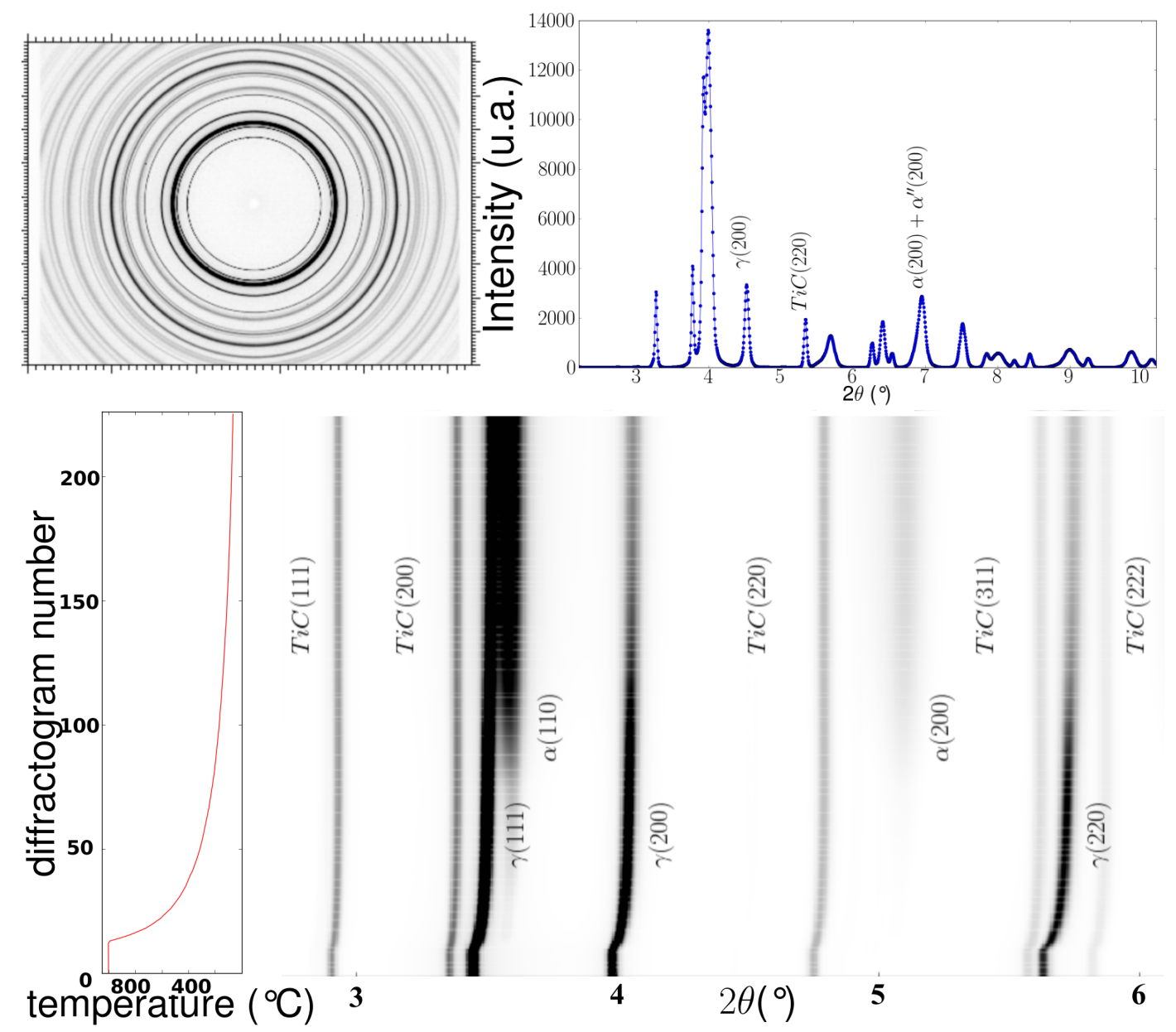

Fig. 2: (top left) XRD frame from CCD detector at room temperature, (top right) XRD diagram after correction and reduction at room temperature, (bottom) evolution of diffractograms during cooling

corresponds to a given pair of angle $(\Phi, \Psi)$ that can determined by the following equations $[11,12]$ :

$$
\cos \Psi=\operatorname{cosc}\left(\left(1-\frac{\sin ^{2} \theta \sin ^{2} \delta}{1-\cos ^{2} c}\right)\left(1-\frac{\sin ^{2} \omega \sin ^{2} \delta}{1-\cos ^{2} c}\right)\right)^{1 / 2}-\frac{\sin \omega \sin \theta \sin ^{2} \delta}{1-\cos ^{2} c}
$$

where

$$
\begin{gathered}
\cos c=\cos \theta \cos \omega+\sin \theta \sin \omega \cos \delta \\
\Phi=\chi+\arccos \left(\frac{\sin (\theta-\omega)}{\sin \Psi}\right)
\end{gathered}
$$

with $\theta$ as the Bragg angle, $\chi$ as the sample rotation and $\omega$ as the sample tilt. Thus, pairs of angle $(\Phi$, $\Psi$ ) are distributed as shown on the figure 3 versus their position on the ring (azimuth $\delta$ ).

Finally, the " $\sin ^{2} \psi^{\prime \prime}$ method can be applied. The deformation $\epsilon_{\Phi \Psi}$ in the direction normal to the diffracting plane defined by $\Phi$ and $\Psi$ angles is expressed as a function of the components of the deformation tensor in the sample reference system :

$$
\begin{gathered}
\left(\begin{array}{ccc}
\epsilon_{11} & \epsilon_{12} & \epsilon_{13} \\
\epsilon_{21} & \epsilon_{22} & \epsilon_{23} \\
\epsilon_{31} & \epsilon_{32} & \epsilon_{33}
\end{array}\right)[13]: \\
\epsilon_{\Phi \Psi}=\ln \left(\frac{\sin \theta_{0}}{\sin \theta}\right)=\left[\left(\epsilon_{11} \cos ^{2} \Phi+\epsilon_{12} \sin 2 \Phi+\right.\right. \\
\left.\left.\epsilon_{22} \sin ^{2} \Phi\right)-\epsilon_{33}\right] \sin ^{2} \Psi+\left(\epsilon_{13} \cos \Phi+\epsilon_{23} \sin \Phi\right) \sin 2 \Psi+\epsilon_{33}
\end{gathered}
$$




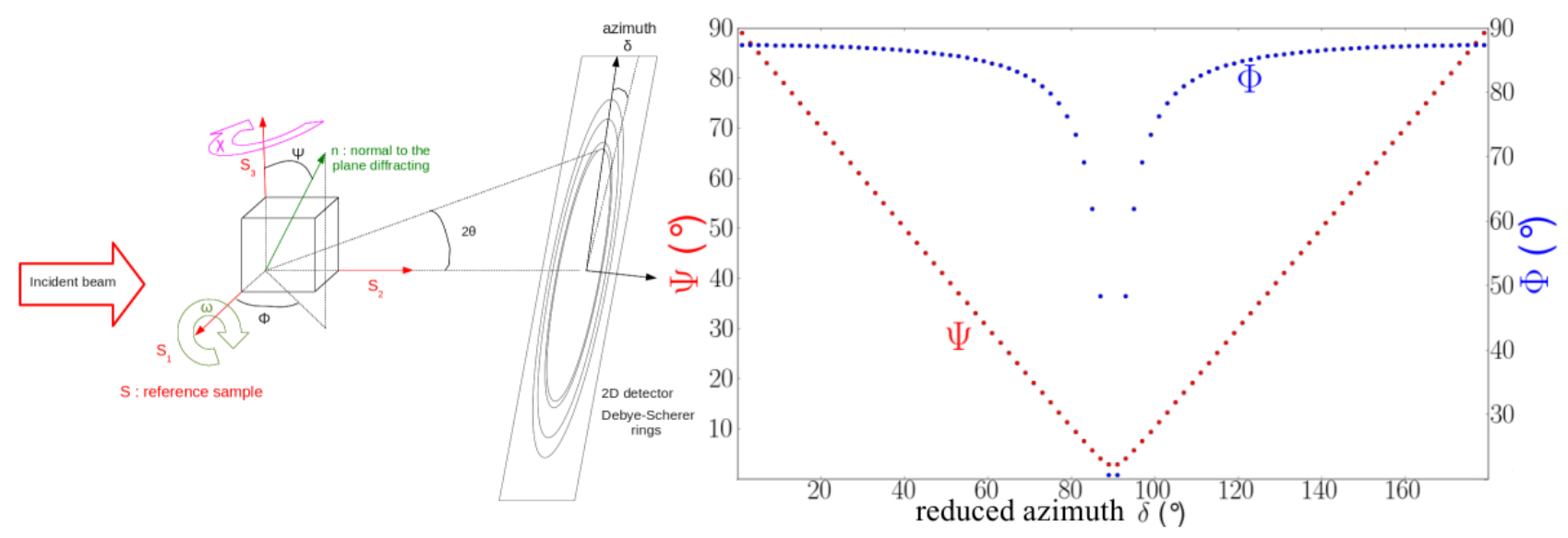

Fig. 3: (left) angles from setup configuration : (S1, S2, S3) is the sample reference system and $(\Phi, \Psi)$ define the direction normal to diffracting plane hkl

Introducing Hooke's law, $\epsilon_{\Phi \Psi}$ can be expressed as a function of the components of the stress tensor :

$$
\begin{gathered}
\epsilon_{\Phi \Psi}=\ln \left(\frac{\sin \theta_{0}}{\sin \theta}\right)=\frac{1+\nu_{h k l}}{E_{h k l}}\left(\sigma_{\Phi}-\sigma_{33}\right) \sin ^{2} \Psi+\frac{1+\nu_{h k l}}{E_{h k l}} \tau_{\Phi} \sin 2 \Psi+\frac{1+\nu_{h k l}}{E_{h k l}} \sigma_{33}-\frac{\nu_{h k l}}{E_{h k l}} \operatorname{Tr}(\overline{\bar{\sigma}}) \\
\sigma_{\phi}=\sigma_{11} \cos ^{2} \phi+\sigma_{12} \sin 2 \phi+\sigma_{22} \sin ^{2} \phi \\
\tau_{\phi}=\sigma_{13} \cos \phi+\sigma_{23} \sin \phi \\
\operatorname{Tr}(\overline{\bar{\sigma}})=\sigma_{11}+\sigma_{22}+\sigma_{33}
\end{gathered}
$$

$E_{h k l}$ and $\nu_{h k l}$ are the radiocrystallographic elastic constants (Young's modulus and Poisson's ratio). $\theta_{0}$ is the diffraction angle for the diffracting plane without stress.

Then, $\ln \left(\frac{1}{\sin \theta}\right)=f\left(\sin ^{2} \Psi\right)$ is plotted for each phase. In our case, a linear approximation can be made, thus neglecting shear stresses. The slope of this straight line allows to get the stress difference $\sigma_{\Phi}-\sigma_{33}$. In our configuration (fig. 3), we can only obtain the $\sin ^{2} \Psi$ plot for $\Phi$ close to $90^{\circ}$ and thus get only $\sigma_{22}-\sigma_{33}$. For our analysis, we have used the isotropic elastic constants (Young's modulus E and Poisson's ratio $\nu$ ). For the steel, the evolutions of $\mathrm{E}$ and $\nu$ with temperature are taken from litterature [14]. For the Young's modulus of the TiC reinforcements, E changes with temperature according to : $\mathrm{E}=-69.87 \mathrm{~T}\left({ }^{\circ} \mathrm{C}\right)+480.10^{3}(\mathrm{MPa})$ and Poisson's ratio is 0.3 [15]. Given the amount of data to treat (about 800000 diffraction peaks for the case presented hereafter), we have developed an automatic procedure.

\section{Results}

Kinetics of phase transformation. We present the evolution of the phase fraction, the mean cell parameters and stresses difference during the cooling from $1000^{\circ} \mathrm{C}$ to $50^{\circ} \mathrm{C}$ at nearly $5^{\circ} \mathrm{C} / \mathrm{s}$, leading mainly to the formation of martensite in the matrix (fig. 4).

At the beginning of the cooling, only austenite $(\gamma)$ and $\mathrm{TiC}$ are present with $81 \% \gamma$ and $19 \% \mathrm{TiC}$. Ferrite $\left(\alpha, \mathrm{BCC}\right.$ structure) appears at $815^{\circ} \mathrm{C}$ and this amount increases slowly until $190^{\circ} \mathrm{C}$ where it reaches nearly $6 \%$. At $190^{\circ} \mathrm{C}$, the martensitic transformation ( $\alpha^{\prime}$ tetragonal structure) begins. During the cooling, the amount of TiC remains roughly constant and the amount of austenite decreases slowly during the ferritic transformation then more quickly during the martensitic transformation. We have assumed that the amount of ferrite remains constant during the martensitic transformation because diffraction peaks of ferrite and martensite overlap and cannot be distinguished.

Mean cell parameters evolutions. From the beginning of cooling and until the beginning of martensitic transformation, the cell parameters of the different phases decrease continuously with small changes of slope. From previous analysis [16] of the apparent coefficient of thermal expansion (CTE), 


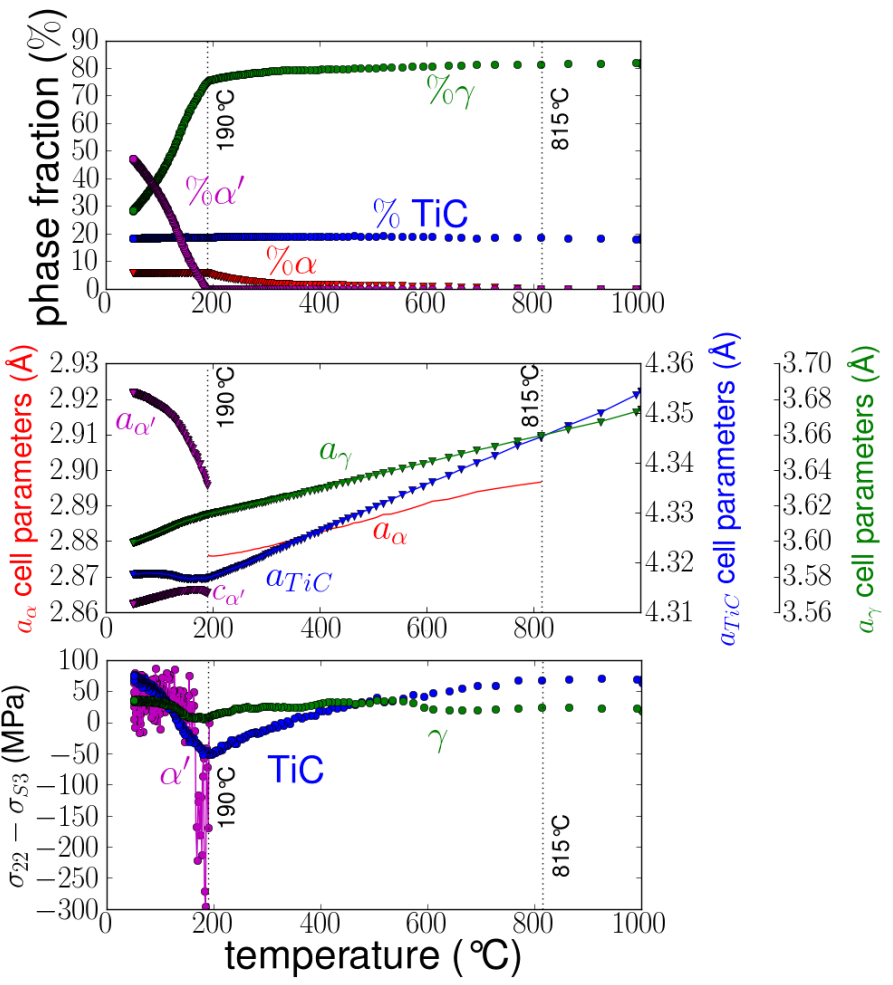

Fig. 4: (top) kinetics of phase transformation during cooling (center) cell parameter evolutions during cooling (bottom) stress difference evolutions during cooling

it was concluded that during cooling, thermal stresses are generated in the phases. TiC is under a mean compression state and the austenite under a mean tension state since the CTE of austenite is about 3 times larger than the one of TiC. As the martensitic transformation occurs, TiC cell parameter increases and austenite cell parameter decreases (as the martensite content reaches about 15\%) indicating a decrease of the mean compression in $\mathrm{TiC}$ and of the mean tension in austenite due to the volumic expansion associated with the transformation.

Stress difference evolutions. It can be noticed that for $\mathrm{TiC}$ particles and austenite the stress differences are small and of the order of magnitude of uncertainty (nearly $50 \mathrm{MPa}$ ). Nevertheless we can observe that for $\mathrm{TiC}$ particles, from about $800^{\circ} \mathrm{C}$ the stress difference increases continuously with a slope that increases under $400^{\circ} \mathrm{C}$. At $190^{\circ} \mathrm{C}$ (beginning of the martensitic transformation) the evolution of the stress difference in $\mathrm{TiC}$ is reversed and the stress difference becomes positive. A change in the slope is also observed for the austenite in the same domain but the amplitudes of the stress difference variations is smaller. The stress difference shows larger negative values in the martensite at the beginning of the transformation but also a large scatter due to overlapping of $\alpha$ and $\alpha^{\prime}$ peaks. These stress difference evolution are very difficult to interpret : indeed, the increase of the stress difference in TiC during cooling (before the martensitic transformation) suggests that the stress state in TiC particles deviates from an hydrostatic one although micromechanical calculations (on a simplified microstructure) show an hydrostatic stress state. But this must be confirmed by new in situ synchrotron experiments allowing to obtain the evolution of the stress difference $\sigma_{11}-\sigma_{33}$ too. In addition the stress free parameters must be determined versus temperature in order to determine $\sigma_{33}$ and to obtain all the components of the stress tensor. 


\section{Concluding remarks}

We have developed a methodology for robust and fast stress analysis starting from 2D images i.e. Debye-Scherrer rings obtained by in situ synchrotron $\mathrm{X}$ ray diffraction experiments. From the present experiments performed during heat treatment of a steel matrix composite, we can get only the evolutions of the stress difference $\left(\sigma_{22}-\sigma_{33}\right)$ in the different phases $\gamma, \alpha$ and TiC. We have shown that the stress difference evolutions in the TiC particles and in the austenite show changes that are correlated with the martensitic transformation of the austenite. Further experiments (with a rotation of the sample) are necessary in order to be able to perform a full $\sin ^{2} \Psi$ analysis and get, all the components of the stress tensor. The micromechanical approach [6] will be further developed in 3D in order to interpret the experimental evolutions of the mean internal stress states in the different phases during cooling.

\section{Aknowledgments}

The authors gratefully acknowledge Mecachrome for supplying the materials, the Direction Générale des Entreprises (DGE) for financial support in the AMETIS program and the European Synchrotron Radiation Facility (ESRF) for provision of beamtime at beamline ID15B. This work was supported by the French State through the program "Investment in the future" operated by the National Research Agency (ANR) and referenced by ANR-11-LABX-0008-01 (LabEx DAMAS).

\section{References}

[1] M. Meixner, M. Fitzpatrick and W. Reimers : Composite Science and Technology, Vol. 71 (2011), p. $167-176$

[2] R. Lee, G. Chen and B. Hang : Composites, Vol. 26 (1995), p. 425-429

[3] E. Pagounis, E. Haimi, J. Pietikaïnen, M. Talvitie, S. Vahvaselkä and V.K. Lindroos : Scripta Materialia, Vol. 34 (1996), p. 407-413

[4] Y. Wu, M. Wang, Z. Chen, N. Ma and H. Wang : Materials Science, Vol. 48 (2013), p. 2928-2933

[5] M. Mourot, A. Courleux, M. Dehmas, E. Gautier, G. Geandier, O. Dezellus, J.C. Viala and O. Martin, N. Karnatak and F. Danoix : Solid State Phenomena, Vol. 172-174 (2013), p. 747-752

[6] G.Geandier, M. Dehmas, M. Mourot, E. Aeby Gautier, S. Denis, O. Martin and N. Karnatak : Materials Science Forum, Vols. 768-769 (2014), p. 313-320

[7] H.M.A. Rietveld : Journal of Applied Crystallography, Vol. 2 (1969), p. 65-71

[8] J. Rodriguez-Carvajal : Physica B, Vol. 192 (1993), p. 55-59

[9] A.P. Hammersley, S.O. Svensson, A. Thompson, H. Graafsma, A. Kvick and J.P. Moy : Review of Scientific Instrument, Vol. 66 (1995), p. 2729-2733

[10] C. Le Bourlot: PhD Thesis Paris 13, (2012)

[11] F. Heidelbach, C. Riekel and H.R. Wenk : Journal of Applied Crystallography, Vol. 32 (1999), p. $841-849$

[12] M. Gelfi, E. Bontempi, R. Roberti and L.E. Depero : Acta Materialia, Vol. 52 (2004), p. 29282933 
[13] I.C. Noyan and J.B. Cohen : Measurement by diffraction and interpretation in residual stress, Springer-Verlag, (1987)

[14] G. Vidal, P. Lescop and L. Raymondin, Revue de métallurgie XLVIII, Vol. 11 (1951), p. 864-874

[15] J. Wall, H. Choo, T. N. Tiegs and P. K. Liaw : Materials Science and Engineering A, Vol. 421 (2006), p. 40-45

[16] G. Geandier, M. Salib, M. Mourot, L. Vautrot, M. Dehmas, B. Denand, E. Aeby-Gautier and S. Denis : S. Van Hoa P. Hubert (Eds.), ICCM19 - 19th International Conference on Composite Materials, (2013), p. 1732-1741 